\title{
Reductive nitrosylation of ferric human serum heme-albumin
}

\author{
Paolo Ascenzi ${ }^{1,2, *}, Y_{u} \mathrm{Cao}^{1,3, *}$, Alessandra di Masi ${ }^{1}$, Francesca Gullotta ${ }^{1}$, Giampiero De Sanctis ${ }^{4}$, \\ Gabriella Fanali ${ }^{5}$, Mauro Fasano ${ }^{5}$ and Massimo Coletta ${ }^{3,6}$ \\ 1 Department of Biology, University Roma Tre, Italy \\ 2 National Institute for Infectious Diseases I.R.C.C.S. "Lazzaro Spallanzani", Roma, Italy \\ 3 Department of Experimental Medicine and Biochemical Sciences, University of Roma 'Tor Vergata', Italy \\ 4 Department of Molecular, Cellular and Animal Biology, University of Camerino, Italy \\ 5 Department of Structural and Functional Biology, and Center of Neuroscience, University of Insubria, Busto Arsizio (VA), Italy \\ 6 Interuniversity Consortium for the Research on the Chemistry of Metals in Biological Systems, Bari, Italy
}

\section{Keywords \\ ferric human serum heme-albumin; irreversible reductive nitrosylation; kinetics; reversible nitrosylation; thermodynamics \\ Correspondence \\ P. Ascenzi, Department of Biology, University Roma Tre, Viale Guglielmo Marconi 446, I-00146 Roma, Italy \\ Fax: +390657336321 \\ Tel: +390657333494 \\ E-mail: ascenzi@uniroma3.it \\ *These authors contributed equally to this study}

(Received 22 December 2009, revised 17 February 2010, accepted 25 March 2010)

doi:10.1111/j.1742-4658.2010.07662.x
Heme endows human serum albumin (HSA) with heme-protein-like reactivity and spectroscopic properties. Here, the kinetics and thermodynamics of reductive nitrosylation of ferric human serum heme-albumin [HSA-heme$\mathrm{Fe}(\mathrm{III})]$ are reported. All data were obtained at $20^{\circ} \mathrm{C}$. At $\mathrm{pH} 5.5$, HSA-heme-Fe(III) binds nitrogen monoxide (NO) reversibly, leading to the formation of nitrosylated HSA-heme-Fe(III) [HSA-heme-Fe(III)-NO]. By contrast, at $\mathrm{pH} \geq 6.5$, the addition of NO to HSA-heme-Fe(III) leads to the transient formation of HSA-heme-Fe(III)-NO in equilibrium with HSA-heme-Fe(II)-NO ${ }^{+}$. Then, HSA-heme-Fe(II)-NO ${ }^{+}$undergoes nucleophilic attack by $\mathrm{OH}^{-}$to yield ferrous human serum heme-albumin [HSA-heme-Fe(II)]. HSA-heme-Fe(II) further reacts with NO to give nitrosylated HSA-heme-Fe(II) [HSA-heme-Fe(II)-NO]. The rate-limiting step for reductive nitrosylation of HSA-heme-Fe(III) is represented by the $\mathrm{OH}^{-}$-mediated reduction of HSA-heme-Fe(II)-NO ${ }^{+}$to HSA-heme-Fe(II). The value of the second-order rate constant for $\mathrm{OH}^{-}$-mediated reduction of HSA-heme-Fe(II)-NO ${ }^{+}$to HSA-heme-Fe(II) is $4.4 \times 10^{3} \mathrm{M}^{-1} \cdot \mathrm{s}^{-1}$. The present results highlight the role of HSA-heme-Fe in scavenging reactive nitrogen species.

\section{Introduction}

Human serum albumin (HSA), the most abundant protein in plasma (reaching a blood concentration of about $7.0 \times 10^{-4} \mathrm{M}$ ), is a depot and a carrier for many endogenous and exogenous compounds, affects the pharmacokinetics of many drugs, holds some ligands in a strained orientation which results in their metabolic modification, renders potential toxins harmless by transporting them to disposal sites, accounts for most of the antioxidant capacity of human serum and displays (pseudo-)enzymatic properties [1-13].
HSA is a single, nonglycosylated all- $\alpha$-chain protein of 585 amino acids, which contains three homologous domains (labeled I, II and III). Each domain is composed of two separate helical subdomains (named A and B) connected by random coils. Terminal regions of sequential domains contribute to the formation of interdomain helices linking domain IB to domain IIA, and domain IIB to domain IIIA, respectively [3,7,11,13-21].

The structural organization of HSA provides a variety of ligand-binding sites. The heme binds physiologically

\footnotetext{
Abbreviations

CO, carbon monoxide; G. max Lb, Glycine max leghemoglobin; Hb, hemoglobin; HPX-heme-Fe, hemopexin-heme-Fe; HSA, human serum albumin; HSA-heme-Fe(II), ferrous HSA-heme-Fe; HSA-heme-Fe(II)-NO, nitrosylated HSA-heme-Fe(II); HSA-heme-Fe(III), ferric HSA-heme-Fe; HSA-heme-Fe(III)-NO, nitrosylated HSA-heme-Fe(III); HSA-heme-Fe, human serum heme-albumin; Mb, myoglobin; NO, nitrogen monoxide.
} 
to the fatty acid site 1 , located within the IB subdomain, with high affinity $\left(K_{\text {heme }} \sim 1 \times 10^{-8} \mathrm{M}\right)$. The tetrapyrrole ring is arranged in a D-shaped cavity limited by Tyr138 and Tyr161 residues that provide a $\pi-\pi$ stacking interaction with the porphyrin and supply a donor oxygen (from Tyr161) for the heme-Fe(III)-atom [11,20-22]. Heme endows HSA with heme-protein-like reactivity $[7,20,22-34]$ and spectroscopic properties $[12,23,25,27,32,34-37]$. Remarkably, HSA-heme has been reported to bind nitrogen monoxide (NO) $[24,25,27,30,33,35]$ and to act as a $\mathrm{NO}$ and peroxynitrite scavenger [29,34].

Here, the kinetics and thermodynamics of the reversible nitrosylation of ferric HSA-heme-Fe [HSA-heme$\mathrm{Fe}(\mathrm{III})]$ at $\mathrm{pH} 5.5$ and of the irreversible reductive nitrosylation of HSA-heme-Fe(III) between $\mathrm{pH} 6.5$ and $\mathrm{pH} 9.5$ are reported. The rate-limiting step of reductive nitrosylation of HSA-heme-Fe(III) is represented by the $\mathrm{OH}^{-}$-mediated reduction of ferric nitrosylated HSA-heme-Fe [HSA-heme-Fe(III)-NO] to ferrous HSA-heme-Fe [HSA-heme-Fe(II)]. In turn, HSA-heme-Fe(II) undergoes fast nitrosylation [to HSA-heme-Fe(II)-NO]. This purely fundamental study highlights the role of HSA-heme-Fe in scavenging reactive nitrogen species.

\section{Results}

The kinetics and thermodynamics of reversible nitrosy-

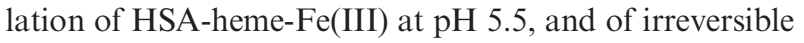
reductive nitrosylation of HSA-heme-Fe(III) between $\mathrm{pH} 6.5$ and $\mathrm{pH} 9.5$, were fitted to the minimum reaction mechanism represented by the following reactions in Scheme 1 [9,38-42]:

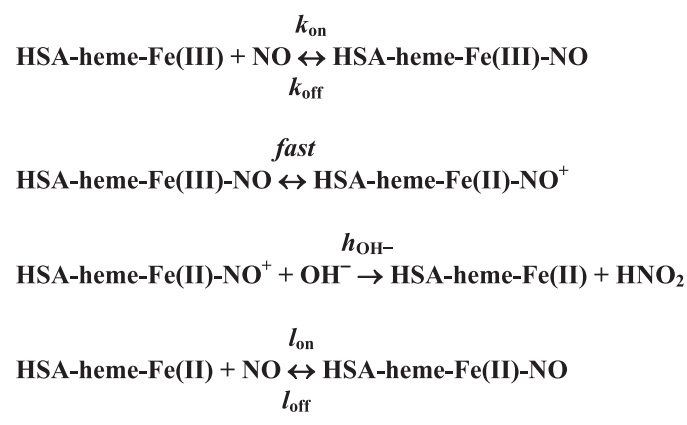

(a)

Scheme 1. HSA-heme-Fe nitrosylation.

\section{Reversible nitrosylation of HSA-heme-Fe(III) at pH 5.5}

The addition of NO to the HSA-heme-Fe(III) solution was accompanied by a shift in the maximum of the optical absorption spectrum in the Soret band from $403 \mathrm{~nm}$ [i.e. HSA-heme-Fe(III)] to $368 \mathrm{~nm}$ [i.e.
HSA-heme-Fe(III)-NO] and a corresponding change of the extinction coefficient from $\varepsilon_{403} \mathrm{~nm}=1.1 \times 10^{5}$ $\mathrm{M}^{-1} \cdot \mathrm{cm}^{-1}$ to $\varepsilon_{368 \mathrm{~nm}}=5.4 \times 10^{4} \mathrm{M}^{-1} \cdot \mathrm{cm}^{-1}$. The reaction was completely reversible as the spectrum reverted to the initial absorption spectrum by merely pumping off gaseous NO or bubbling helium through the HSAheme-Fe(III)-NO solution. The optical absorption spectra of HSA-heme-Fe(III) and HSA-heme-Fe(III)NO observed here correspond to those reported in the literature $[29,35,43]$.

Under all the experimental conditions, the time course for reversible nitrosylation of HSA-heme$\mathrm{Fe}(\mathrm{III})$ conformed to a single-exponential decay for $94-98 \%$ of its course (Fig. 1 and Eqn 1). Values of $k^{\text {obs }}$ were wavelength-independent and NO-independent at a fixed concentration of NO. Figure 1 shows the dependence of $k^{\text {obs }}$ for HSA-heme-Fe(III) nitrosylation on the NO concentration (i.e. [NO]). The analysis of data according to Eqn (2) allowed the values of $k_{\text {on }}\left(=1.3 \times 10^{4} \mathrm{M}^{-1} \cdot \mathrm{s}^{-1}\right)$ and $k_{\text {off }}\left(=2.0 \times 10^{-1} \mathrm{~s}^{-1}\right)$ to be determined, at pH 5.5 and $20^{\circ} \mathrm{C}$ (Table 1).

The dependence of the molar fraction of HSA-heme$\mathrm{Fe}(\mathrm{III})-\mathrm{NO}$ (i.e. $Y$ ) on the NO concentration (i.e. $[\mathrm{NO}]$ ) is shown in Fig. 1. The analysis of data according to Eqn (3) allowed the value of $K(=1.5 \times$ $10^{-5} \mathrm{M}$ ), at pH 5.5 and $20^{\circ} \mathrm{C}$ (Table 1) to be determined. Consistently with the stoichiometry of reaction (a) in Scheme 1, the Hill coefficient $n$ was $1.01 \pm 0.02$. As expected for simple systems [44], the experimentally determined value of $K\left(=1.5 \times 10^{-5} \mathrm{M}\right)$ corresponded to that calculated from $k_{\text {off }}$ and $k_{\text {on }}$ values (i.e. $K=k_{\text {off }} / k_{\text {on }}=1.5 \times 10^{-5} \mathrm{M}$ ).

Note that HSA-heme-Fe(III)-NO does not undergo significant reductive nitrosylation at $\mathrm{pH} 5.5$ and $20^{\circ} \mathrm{C}$ $(<5 \%$ after $30 \mathrm{~min})$.

\section{Irreversible reductive nitrosylation of HSA-heme-Fe(III) between pH 6.5 and pH 9.5}

Mixing the HSA-heme-Fe(III) and NO solutions induced a shift of the optical absorption maximum of the Soret band from $403 \mathrm{~nm}$ [i.e. HSA-heme-Fe(III)] to $368 \mathrm{~nm}$ [i.e. HSA-heme-Fe(III)-NO/HSA-heme$\mathrm{Fe}(\mathrm{II})-\mathrm{NO}^{+}$] and a corresponding change of the extinction coefficient from $\varepsilon_{403 \mathrm{~nm}}=1.1 \times 10^{5} \mathrm{M}^{-1} \cdot \mathrm{cm}^{-1}$ to $\varepsilon_{368 \mathrm{~nm}}=5.4 \times 10^{4} \mathrm{M}^{-1} \cdot \mathrm{cm}^{-1}$. Then, the HSA-heme$\mathrm{Fe}(\mathrm{III})-\mathrm{NO} / \mathrm{HSA}-\mathrm{heme}-\mathrm{Fe}(\mathrm{II})-\mathrm{NO}^{+}$solution underwent a shift of the optical absorption maximum of the Soret band from $368 \mathrm{~nm}$ [i.e. HSA-heme-Fe(III)-NO/HSAheme-Fe(II)-NO ${ }^{+}$] to $389 \mathrm{~nm}$ [i.e. HSA-heme-Fe(II)-NO] and a change of the corresponding extinction coefficient from $\varepsilon_{368 \mathrm{~nm}}=5.4 \times 10^{4} \mathrm{M}^{-1} \cdot \mathrm{cm}^{-1}$ to $\varepsilon_{389 \mathrm{~nm}}=$ $6.3 \times 10^{4} \mathrm{M}^{-1} \cdot \mathrm{cm}^{-1}$. The reaction was irreversible 

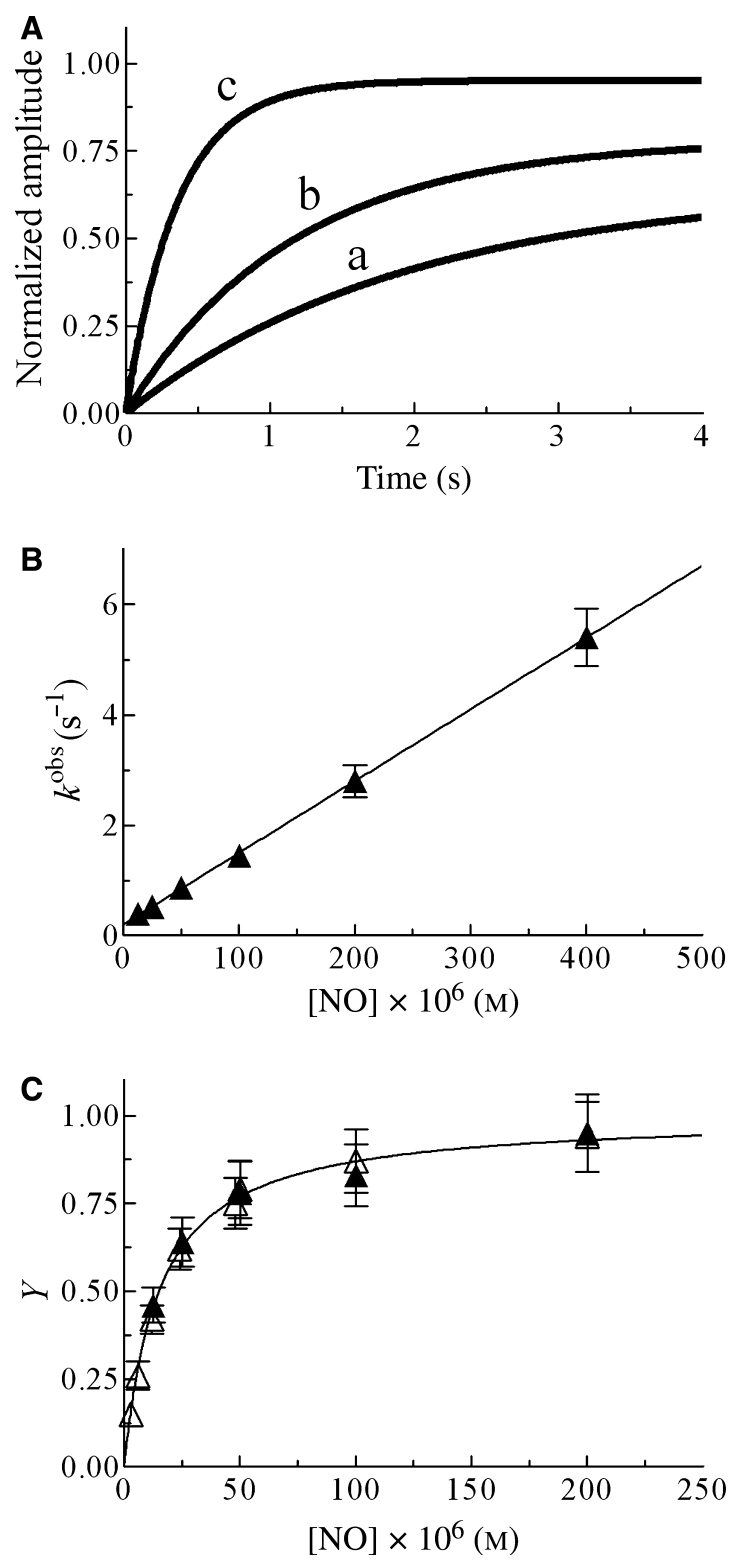

Fig. 1. NO binding to HSA-heme-Fe(III), at pH 5.5 and $20^{\circ} \mathrm{C}$. (A) Normalized averaged time courses of HSA-heme-Fe(III) nitrosylation. The NO concentrations were $2.5 \times 10^{-5} \mathrm{M}$ (trace a), $5.0 \times 10^{-5} \mathrm{M}$ (trace b) and $2.0 \times 10^{-4} \mathrm{M}$ (trace c). The time course analysis according to Eqn (1) allowed the determination of the following values of $k^{\mathrm{obs}}$ and $Y$ : trace $a, k^{\mathrm{obs}}=5.2 \times 10^{-1} \mathrm{~s}^{-1}$ and $Y=0.64$; trace $\mathrm{b}, k^{\mathrm{obs}}=8.7 \times 10^{-1} \mathrm{~s}^{-1}$ and $Y=0.78$; and trace $\mathrm{c}$, $k^{\text {obs }}=2.8 \mathrm{~s}^{-1}$ and $Y=0.95$. (B) Dependence of $k^{\text {obs }}$ for HSA-heme$\mathrm{Fe}$ (III) nitrosylation on [NO]. The continuous line was generated from Eqn (2) with $k_{\text {on }}=(1.3 \pm 0.2) \times 10^{4} \mathrm{M}^{-1} \cdot \mathrm{s}^{-1}$ and $k_{\text {off }}=$ $(2.0 \pm 0.2) \times 10^{-1} \mathrm{~s}^{-1}$. (C) Dependence of $Y$ for HSA-heme-Fe(III) nitrosylation on free [NO]. Open and filled triangles indicate values of $Y$ obtained from equilibrium and kinetic experiments, respectively. The continuous line was generated from Eqn (3) with $K=(1.5 \pm 0.2) \times 10^{-5} \mathrm{M}$. The HSA-heme-Fe(III) concentration was $3.3 \times 10^{-6} \mathrm{M}$. The equilibration time was $10 \mathrm{~min}$. For details, see the text. because the spectrum of HSA-heme-Fe(II)-NO reverted to HSA-heme-Fe(II) instead of to HSA-heme$\mathrm{Fe}(\mathrm{III})$ by merely pumping off gaseous $\mathrm{NO}$ or by bubbling helium through the HSA-heme-Fe(II)-NO solution; however, the denitrosylation process needs about $12 \mathrm{~h}$ for completion.

The optical absorption spectra of the HSA-heme derivatives observed here correspond to those reported in the literature $[29,35,43]$. Free HSA-heme-Fe(II) was never detected spectrophotometrically because of the very rapid reaction between HSA-heme-Fe(II) and NO $\left(l_{\text {on }} \geq 1.2 \times 10^{7} \mathrm{M}^{-1} \cdot \mathrm{s}^{-1}\right.$; see Table 1$)$.

Over the whole NO concentration range explored, the time course for HSA-heme-Fe(III) reductive nitrosylation corresponded to a biphasic process (Fig. 2 and Eqn 4); values of $k^{\text {obs }}$ and $h^{\text {obs }}$ were wavelength-independent at a fixed concentration of NO. The first step of kinetics for HSA-heme-Fe(III) reductive nitrosylation (indicated by $k_{\mathrm{on}}$ in Scheme 1) was a bimolecular process, as observed under pseudo-first-order conditions (Fig. 2). Plots of $k^{\text {obs }}$ versus [NO] were linear (Eqn 2), the slope corresponding to $k_{\text {on }}$. Values of $k_{\text {on }}$ ranged between $7.5 \times 10^{3}$ and $2.4 \times 10^{4} \mathrm{M}^{-1} \cdot \mathrm{s}^{-1}$ over the $\mathrm{pH}$ range explored (Table 1). The $y$ intercept of plots of $k^{\text {obs }}$ versus [NO] corresponded to $k_{\text {off }}$; the values of $k_{\text {off }}$ ranged between $1.9 \times 10^{-1}$ and $4.8 \times$ $10^{-1} \mathrm{~s}^{-1}$ (Table 1). By contrast, the second step (indicated by $h^{\text {obs }}$ in Scheme 1) followed an [NO]-independent monomolecular behavior (Fig. 2) at all $\mathrm{pH}$ values investigated. According to Scheme 1, the value of $h^{\text {obs }}$ increased linearly on increasing $\left[\mathrm{OH}^{-}\right]$(i.e. from $\mathrm{pH}$ 6.5 to 9.5; see Fig. 3, Table 1 and Eqn 5). The slope and the $y$ intercept of the plot of $h^{\text {obs }}$ versus $\left[\mathrm{OH}^{-}\right]$ corresponded to $h_{\mathrm{OH}^{-}}\left(=4.4 \times 10^{3} \mathrm{M}^{-1} \cdot \mathrm{s}^{-1}\right)$ and to $h_{\mathrm{H}_{2} \mathrm{O}}\left(=3.5 \times 10^{-4} \mathrm{~s}^{-1}\right)$, respectively (Table 1$)$.

Between $\mathrm{pH} 6.5$ and $\mathrm{pH} 9.5$, the molar fraction of HSA-heme-Fe(III)-NO (i.e. $Y$ ) increased on free [NO], tending to level off at $[\mathrm{NO}]>10 \times K$, according to Eqn (3). The analysis of data according to Eqn (3) allowed us to determine values of $K$, ranging between $1.3 \times 10^{-5}$ and $3.1 \times 10^{-5} \mathrm{M}$, at $20^{\circ} \mathrm{C}$ over the $\mathrm{pH}$ range investigated (Table 1). According to the HSAheme-Fe(III) : NO 1: 1 stoichiometry of reaction (a) in Scheme 1, the Hill coefficient $n$ was $1.00 \pm 0.02$. As expected for a simple system [44], values of $K$ corresponded to those of $k_{\text {off }} / k_{\text {on }}$, under all the experimental conditions investigated (Table 1).

\section{Determination of nitrite, nitrate and $S$-nitrosothiols}

The concentrations of nitrite, nitrate and $S$-nitrosothiols were determined after HSA-heme-Fe(III) reductive 
Table 1. Values of thermodynamic and kinetic parameters for reductive nitrosylation of HSA-heme-Fe(III), at $20^{\circ} \mathrm{C}$. ND, not determined.

\begin{tabular}{|c|c|c|c|c|c|c|c|c|c|}
\hline $\mathrm{pH}$ & $K(\mathrm{M})$ & $k_{\text {on }}\left(\mathrm{M}^{-1} \cdot \mathrm{s}^{-1}\right)$ & $k_{\text {off }}\left(\mathrm{s}^{-1}\right)$ & $k_{\text {off }} / k_{\text {on }}(\mathrm{M})$ & $h^{\mathrm{obs}}\left(\mathrm{s}^{-1}\right)$ & $L(M)$ & $I_{\text {on }}\left(\mathrm{M}^{-1} \cdot \mathrm{s}^{-1}\right)$ & $I_{\text {off }}\left(\mathrm{s}^{-1}\right)$ & $I_{\text {off }} / I_{\text {on }}(\mathrm{M})$ \\
\hline 5.5 & $1.5 \times 10^{-5}$ & $1.3 \times 10^{4}$ & $2.0 \times 10^{-1}$ & $1.5 \times 10^{-5}$ & $a_{-}$ & $\leq 3.3 \times 10^{-8}$ & $1.6 \times 10^{7}$ & $1.3 \times 10^{-4}$ & $8.1 \times 10^{-12}$ \\
\hline 6.5 & $2.9 \times 10^{-5}$ & $1.5 \times 10^{4}$ & $4.8 \times 10^{-1}$ & $3.2 \times 10^{-5}$ & $2.1 \times 10^{-4}$ & $\leq 3.3 \times 10^{-8}$ & ND & $2.4 \times 10^{-4}$ & $N D$ \\
\hline 7.5 & $1.8 \times 10^{-5}$ & $2.1 \times 10^{4}$ & $3.1 \times 10^{-1}$ & $1.5 \times 10^{-5}$ & $1.7 \times 10^{-3}$ & $\leq 3.3 \times 10^{-8}$ & $2.1 \times 10^{7}$ & $1.4 \times 10^{-4}$ & $6.7 \times 10^{-12}$ \\
\hline 8.1 & $3.1 \times 10^{-5}$ & $8.5 \times 10^{3}$ & $2.5 \times 10^{-1}$ & $2.9 \times 10^{-5}$ & $6.3 \times 10^{-3}$ & $\leq 3.3 \times 10^{-8}$ & ND & $2.1 \times 10^{-4}$ & ND \\
\hline 8.5 & $1.3 \times 10^{-5}$ & $1.6 \times 10^{4}$ & $1.9 \times 10^{-1}$ & $1.2 \times 10^{-5}$ & $1.4 \times 10^{-2}$ & $\leq 3.3 \times 10^{-8}$ & $1.2 \times 10^{7}$ & $1.7 \times 10^{-4}$ & $1.4 \times 10^{-11}$ \\
\hline 9.0 & $1.9 \times 10^{-5}$ & $2.4 \times 10^{4}$ & $3.6 \times 10^{-1}$ & $1.5 \times 10^{-5}$ & $3.5 \times 10^{-2}$ & $\leq 3.3 \times 10^{-8}$ & ND & $1.9 \times 10^{-4}$ & ND \\
\hline 9.5 & $2.6 \times 10^{-5}$ & $7.5 \times 10^{3}$ & $2.1 \times 10^{-1}$ & $2.8 \times 10^{-5}$ & $1.4 \times 10^{-1}$ & $\leq 3.3 \times 10^{-8}$ & $1.8 \times 10^{7}$ & $2.6 \times 10^{-4}$ & $1.4 \times 10^{-11}$ \\
\hline
\end{tabular}

a HSA-heme-Fe(III)-NO does not undergo significant reductive nitrosylation at $\mathrm{pH} 5.5(<5 \%$ in $30 \mathrm{~min})$.
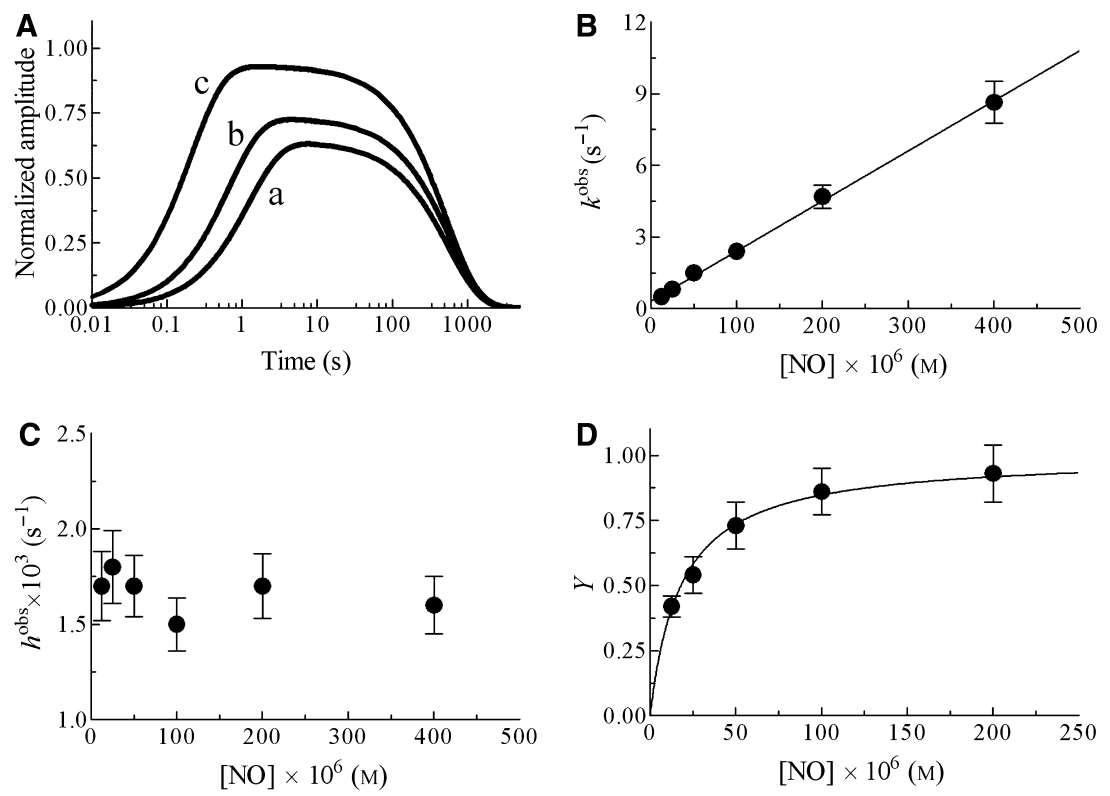

Fig. 2. HSA-heme-Fe(III) reductive nitrosylation, at pH 7.5 and $20^{\circ} \mathrm{C}$. (A) Normalized averaged time courses of HSA-heme-Fe(III) reductive nitrosylation. The NO concentrations were $2.5 \times 10^{-5} \mathrm{M}$ (trace a), $5.0 \times 10^{-5} \mathrm{M}$ (trace b) and $2.0 \times 10^{-4} \mathrm{M}$ (trace c). The time course analysis according to Eqn $(4 \mathrm{a}-\mathrm{c})$ allowed the determination of the following values of $k^{\text {obs }}, h^{\text {obs }}$ and $Y$ : trace $a, k^{\text {obs }}=8.1 \times 10^{-1} \mathrm{~s}^{-1}$, $h^{\text {obs }}=1.8 \times 10^{-3} \mathrm{~s}^{-1}$ and $Y=0.64 ;$ trace $b, \quad k^{\text {obs }}=1.5 \mathrm{~s}^{-1}, \quad h^{\text {obs }}=1.7 \times 10^{-3} \mathrm{~s}^{-1}$ and $Y=0.73 ;$ and trace $c$, $k^{\text {obs }}=4.7 \mathrm{~s}^{-1}$, $h^{\text {obs }}=1.9 \times 10^{-3} \mathrm{~s}^{-1}$ and $Y=0.93$. (B) Dependence of $k^{\text {obs }}$ for HSA-heme-Fe(III) reductive nitrosylation on [NO]. The continuous line was generated from Eqn (2) with $k_{\mathrm{on}}=(2.1 \pm 0.2) \times 10^{4} \mathrm{M}^{-1} \cdot \mathrm{s}^{-1}$ and $k_{\mathrm{off}}=(3.1 \pm 0.3) \times 10^{-1} \mathrm{~s}^{-1}$. (C) Dependence of $h^{\text {obs }}$ for HSA-heme-Fe(III) reductive nitrosylation on [NO]. The average $h^{\text {obs }}$ value is $1.7 \times 10^{-3} \mathrm{~s}^{-1}$. (D) Dependence of $Y$ for HSA-heme-Fe(III) reductive nitrosylation on free [NO]. The continuous line was generated from Eqn (3) with $K=(1.8 \pm 0.2) \times 10^{-5} \mathrm{M}$. The HSA-heme-Fe(III) concentration was $3.3 \times 10^{-6} \mathrm{M}$. For details, see the text.

nitrosylation, at $\mathrm{pH} 7.5$ and $20^{\circ} \mathrm{C}$. As shown in Table 2, reductive nitrosylation of HSA-heme-Fe(III) yielded essentially $\mathrm{NO}_{2}^{-}\left(\mathrm{NO}_{3}^{-}<10 \%\right)$. Under conditions where $[\mathrm{NO}] \leq[\mathrm{HSA}-$ heme-Fe(III) $], \quad\left[\mathrm{NO}_{2}^{-}\right]+$ $\left[\mathrm{NO}_{3}^{-}\right]=1 / 2[\mathrm{NO}]$. However, where $[\mathrm{NO}]=2 \times[\mathrm{HSA}-$ heme-Fe(III)], $\left[\mathrm{NO}_{2}^{-}\right]+\left[\mathrm{NO}_{3}^{-}\right]=[\mathrm{HSA}-$ heme-Fe(III)]. Moreover, the [HSA-heme-Fe(III)] : NO : [HSA-heme$\mathrm{Fe}(\mathrm{II})-\mathrm{NO}]: \mathrm{NO}_{2}^{-}$stoichiometry is $1: 2: 1: 1$. Lastly, $S$-nitrosylation of the single thiol present in HSA (i.e. Cys34) does not significantly occur during reductive nitrosylation of HSA-heme-Fe(III) $(<10 \%$; data not shown).

\section{Reversible nitrosylation of HSA-heme-Fe(II) between $\mathrm{pH} 5.5$ and $\mathrm{pH} \mathbf{9 . 5}$}

The addition of NO (either gaseous or dissolved in the buffer solution) to the HSA-heme-Fe(II) solution brings about a shift in the maximum of the optical absorption spectrum in the Soret band from $418 \mathrm{~nm}$ [i.e. HSA-heme-Fe(II)] to $389 \mathrm{~nm}$ [i.e. HSA-heme$\mathrm{Fe}(\mathrm{II})-\mathrm{NO}]$ and a corresponding change of the extinction coefficient from $\varepsilon_{418 \mathrm{~nm}}=8.7 \times 10^{4} \mathrm{M}^{-1} \cdot \mathrm{cm}^{-1}$ to $\varepsilon_{389 \mathrm{~nm}}=6.4 \times 10^{4} \mathrm{M}^{-1} \cdot \mathrm{cm}^{-1}$. The optical absorption spectra of HSA-heme-Fe(II) and HSA-heme-Fe(II)-NO 


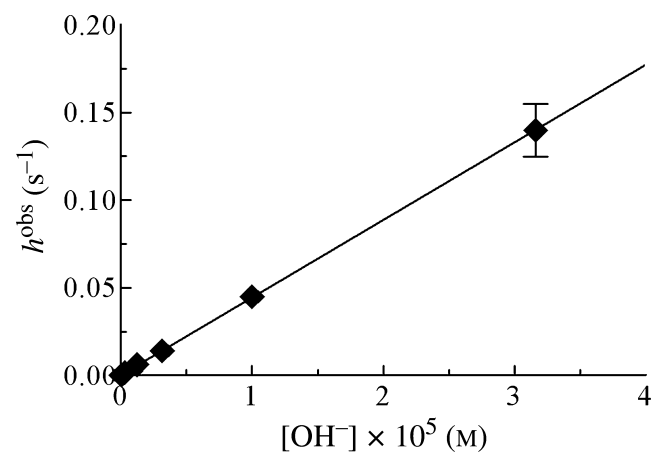

Fig. 3. Dependence of $h^{\text {obs }}$ on $\left[\mathrm{OH}^{-}\right]$for HSA-heme-Fe(III) reductive nitrosylation, at $20^{\circ} \mathrm{C}$. The continuous line was generated from Eqn (5) with $h_{\mathrm{OH}^{-}}=(4.4 \pm 0.3) \times 10^{3} \mathrm{M}^{-1} \cdot \mathrm{s}^{-1}$ and $h_{\mathrm{H}_{2} \mathrm{O}}=$ $(3.5 \pm 0.4) \times 10^{-4} \mathrm{~s}^{-1}$ For details, see the text.

Table 2. $\mathrm{NO}_{2}^{-}$and $\mathrm{NO}_{3}^{-}$concentration obtained by reductive nitrosylation of HSA-heme-Fe(III), at pH 7.5 and $20^{\circ} \mathrm{C}$. The HSAheme-Fe(III) concentration was $1.0 \times 10^{-4} \mathrm{M}$.

\begin{tabular}{|c|c|c|c|}
\hline [NO] (M) & {$\left[\mathrm{NO}_{2}^{-}\right](\mathrm{M})$} & {$\left[\mathrm{NO}_{3}^{-}\right](\mathrm{M})$} & $\begin{array}{l}{\left[\mathrm{NO}_{2}^{-}\right]+} \\
{\left[\mathrm{NO}_{3}^{-}\right](\mathrm{M})}\end{array}$ \\
\hline $5.0 \times 10^{-5}$ & $(2.4 \pm 0.3) \times 10^{-5}$ & $(1.2 \pm 0.2) \times 10^{-6}$ & $2.5 \times 10^{-5}$ \\
\hline $1.0 \times 10^{-4}$ & $(4.7 \pm 0.5) \times 10^{-5}$ & $(3.1 \pm 0.4) \times 10^{-6}$ & $5.0 \times 10^{-5}$ \\
\hline $2.0 \times 10^{-4}$ & $(9.2 \pm 0.9) \times 10^{-5}$ & $(7.1 \pm 0.8) \times 10^{-6}$ & $9.9 \times 10^{-5}$ \\
\hline
\end{tabular}

determined here correspond to those reported in the literature $[25,27,28,32,34,35,43]$. The reaction is completely reversible because the spectrum reverts to the initial absorption spectrum by merely pumping off gaseous NO or bubbling helium through the solution; however, the denitrosylation process needs about $12 \mathrm{~h}$ to be completed.

Under all the experimental conditions investigated, the time course for reversible nitrosylation of HSAheme-Fe(II) conformed to a single-exponential decay for $90-94 \%$ of its course (Fig. 4 and Eqn 6). Values of $l^{\text {obs }}$ were wavelength- and NO-independent at fixed NO concentrations. Figure 4 shows the linear dependence of $l^{\text {obs }}$ for HSA-heme-Fe(II) nitrosylation on the NO concentration (i.e. [NO]). The analysis of data according to Eqn (7) allowed us to determine values of $k_{\text {on }}$ ranging between $1.2 \times 10^{7}$ and $2.1 \times 10^{7} \mathrm{M}^{-1} \cdot \mathrm{s}^{-1}$ (Table 1).

Under all the experimental conditions, the timecourse for HSA-heme-Fe(II)-NO denitrosylation [i.e. NO replacement by carbon monoxide $(\mathrm{CO})$ ] conforms to a single-exponential decay (from 97\% to $102 \%$ ) of its course (Fig. 4). The analysis of data according to Eqn (8) allowed us to determine $l_{\text {off }}$ values ranging between $1.3 \times 10^{-4}$ and $2.6 \times 10^{-4} \mathrm{~s}^{-1}$, at $20{ }^{\circ} \mathrm{C}$ over the $\mathrm{pH}$ range explored (Table 1). Values of $l_{\text {off }}$ are $\mathrm{pH}$-, wavelength- and CO-independent in the presence of an excess of sodium dithionite. The $l_{\text {off }}$ values reported here correspond to those determined previously in the absence of allosteric effectors [24,30,33].

Figure 4 shows the dependence of the molar fraction of HSA-heme-Fe(II)-NO (i.e. $Y$ ) on the NO concentration (i.e. [NO]). The value of $Y$ increased linearly with the NO concentration, reaching the maximum $(=1.0 \pm 0.05)$ at the $1: 1$ HSA-heme-Fe(II):NO molar ratio, even at the minimum HSA-heme-Fe(II) concentration investigated $\left(=3.3 \times 10^{-6} \mathrm{M}\right)$. According to the literature [45], this behavior reflects a very high affinity of NO for HSA-heme-Fe(II), the value of the dissociation equilibrium constant $L$ being lower than that of the HSA-heme-Fe(II) concentration by at least two orders of magnitude; thus, $L \leq 3 \times 10^{-8} \mathrm{M}$ over the whole $\mathrm{pH}$ range explored, at $20^{\circ} \mathrm{C}$ (Table 1 ). As expected for a simple reversible ligand-binding system [44], the values of $L$ agree with those calculated from $l_{\text {on }}$ and $l_{\text {off }}$ (i.e. $L=l_{\text {off }} / l_{\text {on }}$ ), under all the experimental conditions investigated (Table 1).

\section{Discussion}

HSA-heme-Fe(III) undergoes irreversible reductive nitrosylation between $\mathrm{pH} 6.5$ and $\mathrm{pH} 9.5$, under anaerobic conditions. In fact, the addition of $\mathrm{NO}$ to HSA-heme-Fe(III) leads to the transient formation of HSA-heme-Fe(III)-NO in equilibrium with HSA-heme$\mathrm{Fe}(\mathrm{II})-\mathrm{NO}^{+}$. Then, HSA-heme-Fe(II)-NO ${ }^{+}$undergoes nucleophilic attack by $\mathrm{OH}^{-}$to yield HSA-heme-Fe(II). HSA-heme-Fe(II) thus produced reacts further with $\mathrm{NO}$ to give HSA-heme-Fe(II)-NO. By contrast, at pH 5.5, HSA-heme-Fe(III) undergoes fully reversible NO binding. In fact, the HSA-heme-Fe(III)-NO derivative does not convert significantly to HSA-heme-Fe(II)-NO (Fig. 1 and Table 1). The data reported here match well with Scheme 1, the $\mathrm{NO}: \mathrm{NO}_{2}^{-}$stoichiometry being 2:1. Moreover, no significant formation of $S$-nitrosothiol occurs during the reductive nitrosylation of HSA-heme-Fe(III).

The analysis of kinetic and thermodynamic parameters reported in Table 3 allows the following considerations.

(a) The values of $k_{\text {on }}$ and $l_{\text {on }}$ for the reductive nitrosylation of ferric rabbit hemopexin-heme-Fe (HPXheme-Fe) [46] and horse cytochrome $c[38,39]$ are lower than those reported for HSA-heme-Fe (the present study), Glycine max leghemoglobin (G. $\max \mathrm{Lb)}$ [42], sperm whale myoglobin $(\mathrm{Mb})$ $[38,39]$ and tetrameric human hemoglobin $(\mathrm{Hb})$ [39]. This reflects the hexa-coordination of the heme-Fe atom of rabbit HPX-heme-Fe and horse 

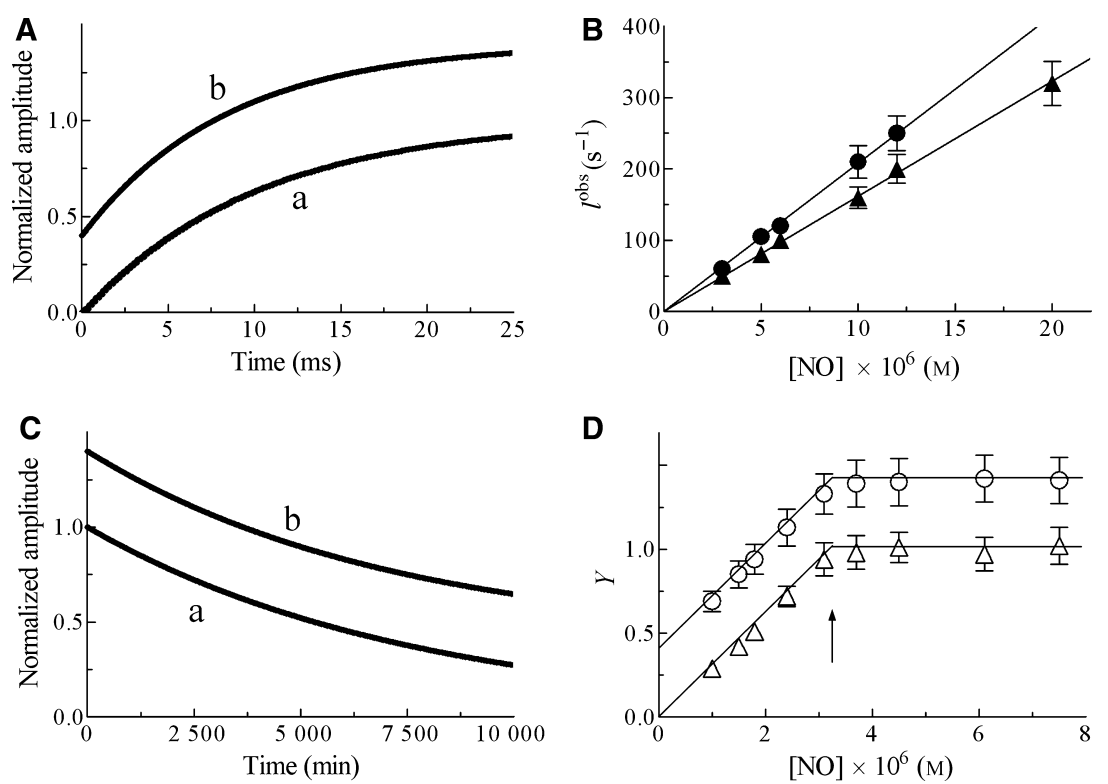

Fig. 4. HSA-heme-Fe(II) nitrosylation at $\mathrm{pH} 5.5$ and 7.5, and at $20^{\circ} \mathrm{C}$. (A) Normalized averaged time course of HSA-heme-Fe(II) nitrosylation at $\mathrm{pH} 5.5$ (trace a) and 7.5 (trace b), and at $20^{\circ} \mathrm{C}$. The time course analysis according to Eqn (6) allowed the determination of the following values of pbs: $1.0 \times 10^{2} \mathrm{~s}^{-1}$ (trace a) and $1.2 \times 10^{2} \mathrm{~s}^{-1}$ (trace b). For clarity, the time course obtained at pH 7.5 was up-shifted by 0.4 . The HSA-heme-Fe(II) and NO concentrations were $1.2 \times 10^{-6}$ and $6.0 \times 10^{-6} \mathrm{M}$, respectively. (B) Dependence of $I^{\text {obs }}$ for HSA-heme-Fe(II) nitrosylation on [NO] at pH 5.5 (triangles) and 7.5 (circles), and at $20^{\circ} \mathrm{C}$. The continuous lines were generated from Eqn (7) using the following values of $I_{\text {on }}:(1.6 \pm 0.2) \times 10^{7} \mathrm{M}^{-1} \cdot \mathrm{s}^{-1}(\mathrm{pH} 5.5)$ and $(2.1 \pm 0.2) \times 10^{7} \mathrm{M}^{-1} \cdot \mathrm{s}^{-1}(\mathrm{pH} 7.5)$. (C) Normalized averaged time courses of HSA-heme$\mathrm{Fe}(\mathrm{II})-\mathrm{NO}$ denitrosylation, at $\mathrm{pH} 5.5$ (trace a) and 7.5 (trace b), and at $20^{\circ} \mathrm{C}$. The time course analysis according to Eqn (8) allowed the determination of the following values of $I_{\text {off }}: 1.3 \times 10^{-4} \mathrm{~s}^{-1}$ (trace a) and $1.4 \times 10^{-4}$ (trace b). For clarity, the time course obtained at $\mathrm{pH} 7.5 \mathrm{was}$ up-shifted by 0.4. The HSA-heme-Fe(II)-NO, CO and sodium dithionite concentrations were $3.3 \times 10^{-6}, 2.0 \times 10^{-4}$ and $1.0 \times 10^{-2} \mathrm{M}$, respectively. (D) Dependence of $Y$ on [NO] for HSA-heme-Fe(II) nitrosylation at pH 5.5 (triangles) and 7.5 (circles), and at $20{ }^{\circ} \mathrm{C}$. The arrow indicates the 1 : 1 molar ratio of HSA-heme-Fe(II) : NO. For clarity, the values of $Y$ obtained at pH 7.5 were up-shifted by 0.4 . The HSA-heme-Fe(II) concentration was $3.3 \times 10^{-6} \mathrm{M}$. For details, see the text.

cytochrome $c$, which must undergo transient penta-coordination to allow exogenous ligand (i.e. NO) binding $[47,48]$.

(b) Values of $k_{\text {off }}$ for $\mathrm{NO}$ dissociation from heme$\mathrm{Fe}(\mathrm{III})$-NO complexes range between $\leq 10^{-4}$ and $1.4 \times 10^{1} \mathrm{~s}^{-1}$, while values of $l_{\text {off }}$ for NO dissociation from heme-Fe(II)-NO complexes are always $\leq 10^{-3} \mathrm{~s}^{-1}$. This may reflect the different stabilization mode of the heme-Fe bound (e.g. NO) by heme distal residues [32,47-53].

(c) Although values of $k_{\text {on }}$ and $k_{\text {off }}$ for NO binding to heme-Fe(III) proteins are very different, values of $K\left(=k_{\text {off }} / k_{\text {on }}\right)$ are closely similar, indicating the occurrence of kinetic compensation phenomena. By contrast, values of $L\left(=l_{\text {off }} / l_{\text {on }}\right)$ are markedly different, primarily as a result of $l_{\text {on }}$ values. As a whole, this may reflect the interplay between the redox state of the heme-Fe atom and the nitrosylation process.

(d) The $h_{\mathrm{OH}^{-}}$value for reductive nitrosylation of rabbit HPX-heme-Fe(III) $\left(\geq 7 \times 10^{5} \mathrm{M}^{-1} \cdot \mathrm{s}^{-1}\right)$ [46] is larger than those reported for HSA-heme-Fe(III) (the present study), horse cytochrome $c$ (III) [38,39], G. max Lb(III) [42], sperm whale $\mathrm{Mb}$ (III) [38,39] and human $\mathrm{Hb}$ (III) [39], ranging between $3.2 \times 10^{2}$ and $4.4 \times 10^{3} \mathrm{M}^{-1} \cdot \mathrm{s}^{-1}$. This may reflect different anion accessibility to the heme pocket $[44,54]$ and heme-protein reduction potentials $[39,42]$.

(e) Although the values of $h_{\mathrm{OH}^{-}}$and $h_{\mathrm{H}_{2} \mathrm{O}}$ cannot be compared directly, $\mathrm{OH}^{-}$ions catalyze reductive nitrosylation of $\mathrm{HSA}-\mathrm{heme}-\mathrm{Fe}(\mathrm{II})-\mathrm{NO}^{+}$much more efficiently than $\mathrm{H}_{2} \mathrm{O}$ (the present study), as previously reported for G. max $\mathrm{Lb}(\mathrm{III})$ [42] and human $\mathrm{Hb}(\mathrm{III})$ [39], reflecting the role of $\mathrm{OH}^{-}$in heme-Fe(II) formation [39]. According to the literature $[39,42]$, the $\mathrm{pH}$ dependence of $h^{\text {obs }}$ has been attributed to changes of the $\mathrm{OH}^{-}$concentration. The linear dependence of $h^{\mathrm{obs}}$ on $\left[\mathrm{OH}^{-}\right]$indicates that no additional elements appear to be involved in irreversible reductive nitrosylation of HSAheme-Fe(III) (see Scheme 1, Eqn 5 and Fig. 3). 


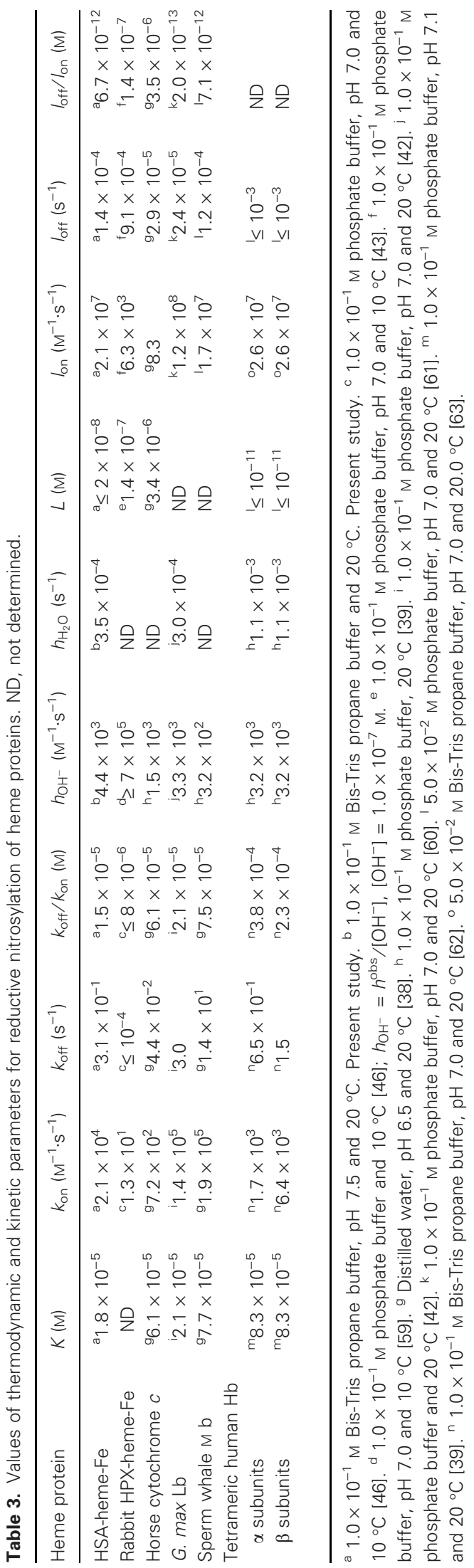

However, we cannot exclude that the observed $\mathrm{pH}$ effects could also reflect reversible $\mathrm{pH}$-dependent conformational transitions of HSA. In fact, between $\mathrm{pH} 4.3$ and $\mathrm{pH}$ 8.0, HSA displays the neutral form, while at $\mathrm{pH}>8.0$, HSA exhibits the basic form $[3,9,36,37]$.

(f) Different rate-limiting steps affect the reductive nitrosylation of heme-Fe(III) proteins. Indeed, reductive nitrosylation of HSA-heme-Fe(III) (the present study), G. max Lb(III) [42], sperm whale $\mathrm{Mb}$ (III) [39] and human $\mathrm{Hb}(\mathrm{III})$ [39] is limited by the $\mathrm{OH}^{-}$-mediated reduction of HSA-heme-Fe(II)$\mathrm{NO}^{+}$to HSA-heme-Fe(II) (reaction (c) in Scheme 1). By contrast, NO binding to hexa-coordinated rabbit HPX-heme(III) and horse cytochrome $c$ (III) (reaction (a) in Scheme 1) represents the rate-limiting step $[39,46]$.

The present results highlight the role of HSA-heme$\mathrm{Fe}$ in the scavenging of reactive nitrogen species. In fact, HSA-heme-Fe(III) facilitates the conversion of $\mathrm{NO}$ to $\mathrm{NO}_{2}^{-}$(reaction (c) in Scheme 1, and Table 2; the present study) and peroxynitrite isomerization to $\mathrm{NO}_{3}^{-}$[34]. Moreover, HSA-heme-Fe(II)-NO catalyzes peroxynitrite detoxification [29]. NO and peroxynitrite scavenging by HSA-heme-Fe (the present study and $[29,34])$ could occur in patients displaying a variety of severe hemolytic diseases characterized by excessive intravascular hemolysis [29,34]. In fact, under these pathological conditions, the HSA-heme-Fe plasmatic level increases from the low physiological concentration (approximately $1 \times 10^{-6} \mathrm{M}$ ), which appears to be irrelevant for catalysis, to high concentrations $\left(>1 \times 10^{-5} \mathrm{M}\right)$, which appear to be enzymatically relevant [34].

Lastly, HSA, acting not only as a heme carrier but also displaying transient heme-based properties, represents a case for 'chronosteric effects' [31], which opens the scenario towards the possibility of a time- and metabolite-dependent multiplicity of roles for HSA.

\section{Materials and methods}

\section{Materials}

HSA (essentially fatty-acid free, $\geq 96 \%$ ), hemin [iron(III)protoporphyrin(IX)], Bis-Tris propane and Mes were obtained from Sigma-Aldrich (St Louis, MO, USA). Gaseous NO was purchased from Aldrich Chemical Co. (Milwaukee, WI, USA) and purified by flowing through a $\mathrm{NaOH}$ column in order to remove acidic nitrogen oxides. $\mathrm{CO}$ was purchased from Linde AG (Höllriegelskreuth, Germany). All other chemicals were obtained from Sigma-Aldrich and Merck AG (Darmstadt, Germany). All 
products were of analytical or reagent grade and used without purification unless stated otherwise.

The HSA-heme-Fe(III) solution $\left(1.2 \times 10^{-6}, 3.3 \times 10^{-6}\right.$ and $2.0 \times 10^{-4} \mathrm{M}$ ) was prepared by adding a $0.7 \mathrm{M}$ defect of the heme-Fe(III) stock solution $\left(1.0 \times 10^{-2} \mathrm{M} \mathrm{NaOH}\right)$ to the HSA solution $\left(1.0 \times 10^{-1} \mathrm{M}\right.$ Mes, $\mathrm{pH} 5.5$, or $1.0 \times 10^{-1} \mathrm{M}$ Bis-Tris propane, $\mathrm{pH} 6.5$ to 9.5$)$ at $20^{\circ} \mathrm{C}$ [35]. Then, the HSA-heme-Fe(III) solution was degassed and kept under helium.

HSA-heme-Fe(II) was prepared by adding very few grains of sodium dithionite to the HSA-heme-Fe(III) solution $\left(1.2 \times 10^{-6}\right.$ and $\left.3.3 \times 10^{-6} \mathrm{M}\right)$ either at $\mathrm{pH} 5.5$ $\left(1.0 \times 10^{-1} \mathrm{M}\right.$ Mes $)$ or between $\mathrm{pH} \quad 6.5$ and $\mathrm{pH} 9.5$ $\left(1.0 \times 10^{-1} \mathrm{M}\right.$ Bis-Tris propane $)$ and $20^{\circ} \mathrm{C}$, under anaerobic conditions [44].

The NO and CO stock solutions were prepared anaerobically by keeping distilled water in a closed vessel under purified $\mathrm{NO}$ or $\mathrm{CO}$, at $760.0 \mathrm{mmHg}$ and $20^{\circ} \mathrm{C}$. The solubility of $\mathrm{NO}$ and $\mathrm{CO}$ in the water is $2.05 \times 10^{-3}$ and $1.03 \times 10^{-3} \mathrm{M}$, respectively, at $760.0 \mathrm{mmHg}$ and $20^{\circ} \mathrm{C}$ [44]. The $\mathrm{NO}$ and $\mathrm{CO}$ stock solutions were diluted with degassed $1.0 \times 10^{-1} \mathrm{M}$ Mes buffer $(\mathrm{pH}$ 5.5) or Bis-Tris propane buffer $(\mathrm{pH}$ 6.5-9.5) to reach the desired concentration $\left(3.0 \times 10^{-6} \mathrm{M} \leq[\mathrm{NO}] \leq 4.0 \times 10^{-4} \mathrm{M}, \quad\right.$ and $\quad 1.0 \times 10^{-4} \mathrm{M} \leq$ $\left.[\mathrm{CO}] \leq 5.0 \times 10^{-4} \mathrm{M}\right)$.

\section{Methods}

Reversible nitrosylation of HSA-heme-Fe(III) at pH 5.5 Values of the pseudo-first-order rate constant (i.e. $k^{\text {obs }}$; reaction (a) in Scheme 1) and of the dissociation equilibrium constant (i.e. $K=k_{\text {off }} / k_{\text {on }}$; reaction (a) in Scheme 1) for HSA-heme-Fe(III) nitrosylation were obtained by mixing the HSA-heme-Fe(III) solution (final concentration $3.3 \times 10^{-6} \mathrm{M}$ ) with the NO solution (final concentration, $3.0 \times 10^{-6}$ to $4.0 \times 10^{-4} \mathrm{M}$ ) under anaerobic conditions. No gaseous phase was present. HSA-heme-Fe(III) nitrosylation was monitored between 350 and $470 \mathrm{~nm}$.

Values of $k^{\text {obs }}$ were obtained according to Eqn (1) [44]:

$[\mathrm{HSA}-\text { heme }-\mathrm{Fe}(\mathrm{III})]_{t}=[\mathrm{HSA}-\text { heme }-\mathrm{Fe}(\mathrm{III})]_{\mathrm{i}} \times \mathrm{e}^{-k^{\mathrm{obs}} \times t}$

Values of the second-order rate constant for HSA-heme$\mathrm{Fe}(\mathrm{III})$ nitrosylation (i.e. $k_{\text {on }}$; reaction (a) in Scheme 1) and of the first-order rate constant for the dissociation of the HSA-heme-Fe(III)-NO adduct (i.e. $k_{\text {off }}$; reaction (a) in Scheme 1) were determined from the dependence of $k^{\text {obs }}$ on [NO], according to Eqn (2) [44]:

$$
k^{\text {obs }}=k_{\text {on }} \times[\mathrm{NO}]+k_{\mathrm{off}}
$$

The value of $K\left(=k_{\text {off }} / k_{\text {on }}\right.$; reaction (a) in Scheme 1) was determined from the dependence of the molar fraction of HSA-heme-Fe(III)-NO (i.e. $Y$ ) on the free NO concentration (i.e. [NO]), according to Eqn (3) [44]:

$$
Y=\frac{[\mathrm{NO}]}{K+[\mathrm{NO}]}
$$

Values of $K, k_{\text {on }}$ and $k_{\text {off }}$ for HSA-heme-Fe(III) nitrosylation (reaction (a) in Scheme 1) were obtained at $\mathrm{pH} 5.5$ (Mes buffer) and $20^{\circ} \mathrm{C}$.

HSA-heme-Fe(III)-NO was also obtained anaerobically by keeping the HSA-heme-Fe(III) solution under purified gaseous $\mathrm{NO}(760 \mathrm{mmHg})$, at $\mathrm{pH} 5.5\left(1.0 \times 10^{-1} \mathrm{M}\right.$ Mes buffer) $[38,39]$.

\section{Irreversible reductive nitrosylation of HSA-heme-Fe(III) between $\mathrm{pH} 6.5$ and $\mathrm{pH} 9.5$}

Values of the pseudo-first-order rate constants (i.e. $k^{\text {obs }}$ and $h^{\text {obs}}$; reactions (a, c) in Scheme 1 , respectively) and of the dissociation equilibrium constant [i.e. $K\left(=k_{\text {off }} / k_{\text {on }}\right)$; reaction (a) in Scheme 1] for HSA-heme-Fe(III) reductive nitrosylation were obtained by mixing the HSA-heme-Fe(III) solution (final concentration $3.3 \times 10^{-6} \mathrm{M}$ ) with the $\mathrm{NO}$ solution (final concentration, $1.2 \times 10^{-5}$ to $4.0 \times 10^{-4} \mathrm{M}$ ) under anaerobic conditions. No gaseous phase was present. HSA-heme-Fe(III) reductive nitrosylation was monitored between 350 and $470 \mathrm{~nm}$.

Values of the pseudo-first-order rate constants $k^{\text {obs }}$ and $h^{\text {obs }}$ were obtained according to Eqn $(4 a-c)[38-42,46,55]$ :

$$
\begin{gathered}
{[\mathrm{Fe}(\mathrm{III})]_{t}=[\mathrm{Fe}(\mathrm{III})]_{\mathrm{i}} \times \mathrm{e}^{-k^{\mathrm{obs}} \times t}} \\
{[\mathrm{Fe}(\mathrm{III})-\mathrm{NO}]_{t}=[\mathrm{Fe}(\mathrm{III})]_{\mathrm{i}}} \\
\times k^{\mathrm{obs}} \times\left(\frac{\mathrm{e}^{-k^{\mathrm{obs}} \times t}}{h^{\mathrm{obs}}-k^{\mathrm{obs}}}+\frac{\mathrm{e}^{-h^{\mathrm{obs}} \times t}}{k^{\mathrm{obs}}-h^{\mathrm{obs}}}\right) \\
{[\mathrm{Fe}(\mathrm{II})-\mathrm{NO}]_{t}=[\mathrm{Fe}(\mathrm{III})]_{\mathrm{i}}-[\mathrm{Fe}(\mathrm{III})]_{t}} \\
+[\mathrm{Fe}(\mathrm{III})-\mathrm{NO}]_{t}
\end{gathered}
$$

Values of $k_{\text {on }}$ and $k_{\text {off }}$ (reaction (a) in Scheme 1) were determined from the dependence of $k^{\text {obs }}$ on [NO], according to Eqn (2) [44].

Values of $K\left(=k_{\text {off }} / k_{\text {on }}\right.$; reaction (a) in Scheme 1) were determined from the dependence of $Y$ on [NO], according to Eqn (3) [44].

The value of the second-order rate constant for $\mathrm{OH}^{-}$-catalyzed conversion of HSA-heme-Fe(II)-NO ${ }^{+}$to HSA-heme$\mathrm{Fe}(\mathrm{II})$ (i.e. $h_{\mathrm{OH}^{-}}$; reaction (c) in Scheme 1) was determined from the dependence of $h^{\mathrm{obs}}$ on $\left[\mathrm{OH}^{-}\right]$according to $\operatorname{Eqn}(5)[38,39]$ :

$$
h^{\mathrm{obs}}=h_{\mathrm{OH}^{-}} \times\left[\mathrm{OH}^{-}\right]+h_{\mathrm{H}_{2} \mathrm{O}}
$$


where $h_{\mathrm{H}_{2} \mathrm{O}}$ is the first-order rate constant for the $\mathrm{H}_{2} \mathrm{O}$ catalyzed conversion of $\mathrm{HSA}-$ heme-Fe(II)-NO ${ }^{+}$to HSA-heme-Fe(II).

Values of $K, k_{\text {on }}, k_{\text {off }}$ and $h^{\text {obs }}$ for HSA-heme-Fe(III) reductive nitrosylation [reactions $(\mathrm{a}, \mathrm{c})$ in Scheme 1] were obtained between $\mathrm{pH} 6.5$ and $\mathrm{pH} 9.5\left(1.0 \times 10^{-1} \mathrm{M}\right.$ Bis-Tris propane buffer) and at $20{ }^{\circ} \mathrm{C}$.

HSA-heme-Fe(III) reductive nitrosylation was also obtained anaerobically by keeping the HSA-heme-Fe(III) solution under purified gaseous $\mathrm{NO}(760 \mathrm{mmHg})$, between pH 6.5 and $\mathrm{pH} 9.5\left(1.0 \times 10^{-1} \mathrm{M}\right.$ Bis-Tris propane buffer $)$ and at $20{ }^{\circ} \mathrm{C}[38,39]$.

\section{Determination of nitrite, nitrate and $S$-nitrosothiols}

The concentrations of nitrite, nitrate and $S$-nitrosothiols were determined after HSA-heme-Fe(III) reductive nitrosylation at $\mathrm{pH} 7.5\left(1.0 \times 10^{-1} \mathrm{M}\right.$ Bis-Tris propane buffer $)$ and at $20{ }^{\circ} \mathrm{C}$. The HSA-heme-Fe(III) concentration was $1.0 \times 10^{-4} \mathrm{M}$. The NO concentration ranged between $5.0 \times 10^{-5}$ and $2.0 \times 10^{-4} \mathrm{M}$. Analysis for nitrite, nitrate and $S$-nitrosothiols was carried out using the Griess and Saville assays, as described previously [34,56-58].

\section{Reversible nitrosylation of HSA-heme-Fe(II) between pH 5.5 and $\mathrm{pH} 9.5$}

Values of the pseudo-first-order rate constant [i.e. $l^{\text {obs; }}$ see Scheme 1, reaction (d)] for HSA-heme-Fe(II) nitrosylation were obtained by mixing the HSA-heme-Fe(II) (final concentration, $1.2 \times 10^{-6} \mathrm{M}$ ) solution with the NO (final concentration, $3.0 \times 10^{-6}$ to $2.0 \times 10^{-5} \mathrm{M}$ ) solution, under anaerobic conditions [44]. No gaseous phase was present. HSA-heme-Fe(II) nitrosylation was monitored between 360 and $460 \mathrm{~nm}$.

Values of $l^{\text {obs }}$ were obtained according to Eqn (6) [44]:

$[\mathrm{HSA}-\text { heme }-\mathrm{Fe}(\mathrm{II})]_{t}=[\mathrm{HSA}-\text { heme }-\mathrm{Fe}(\mathrm{II})]_{\mathrm{i}} \times \mathrm{e}^{-\mathrm{lobs}^{\mathrm{bs}} \times t}$

Values of the second-order rate constant for HSA-heme$\mathrm{Fe}(\mathrm{II})$ nitrosylation [i.e. $l_{\text {on }}$; see Scheme 1, reaction (a)] were determined from the dependence of $l^{\text {obs }}$ on [NO], according to Eqn (7) [44]:

$$
l^{\mathrm{obs}}=l_{\mathrm{on}} \times[\mathrm{NO}]
$$

Values of the first-order rate constant for NO dissociation from HSA-heme-Fe(II)-NO (i.e. for NO replacement with CO; $l_{\text {off }}$; reaction (d) in Scheme 1) were obtained by mixing the HSA-heme-Fe(II)-NO (final concentration, $3.3 \times 10^{-6} \mathrm{M}$ ) solution with the $\mathrm{CO}$ (final concentration, $1.0 \times 10^{-4}$ to $5.0 \times 10^{-4} \mathrm{M}$ ) sodium dithionite (final concentration, $1.0 \times 10^{-2} \mathrm{M}$ ) solution, under anaerobic conditions
$[30,33]$. No gaseous phase was present. Kinetics was monitored between 360 and $460 \mathrm{~nm}$.

The time course for HSA-heme-Fe(II)-NO denitrosylation [i.e. for HSA-heme-Fe(II) carbonylation] was fitted to a single-exponential process according to the minimum reaction mechanism represented by the following reaction in Scheme 2 [30,34]:

$$
\begin{aligned}
& \text { HSA-heme-Fe(II)-NO }+\mathrm{CO} \rightarrow \text { HSA-heme-Fe(II) } \\
& \qquad \begin{array}{l}
\text { fast } \\
+\mathrm{NO}+\mathrm{CO} \rightarrow \text { HSA-heme-Fe(II)-CO }+\mathrm{NO} .
\end{array}
\end{aligned}
$$

Scheme 2. HSA-heme-Fe(II)-NO denitrosylation.

Values of $l_{\text {off }}$ were determined from data analysis according to Eqn (8) [30,34]:

$$
\begin{aligned}
& {[\mathrm{HSA}-\text { heme }-\mathrm{Fe}(\mathrm{II})-\mathrm{NO}]_{t}} \\
& =[\mathrm{HSA}-\text { heme }-\mathrm{Fe}(\mathrm{II})-\mathrm{NO}]_{\mathrm{i}} \times \mathrm{e}^{-l_{\text {off }} \times t}
\end{aligned}
$$

Minimum values of the dissociation equilibrium constant for HSA-heme-Fe(II) nitrosylation (i.e., $L=l_{\text {off }} / l_{\text {on }}$; reaction (d) in Scheme 1) were estimated by titrating the HSAheme-Fe(II) (final concentration $3.3 \times 10^{-6} \mathrm{M}$ ) solution with the NO (final concentration, $1.0 \times 10^{-6}$ to $2.0 \times 10^{-5} \mathrm{M}$ ) solution, under anaerobic conditions. The equilibration time was $5 \mathrm{~min}$. No gaseous phase was present. Thermodynamics was monitored between 360 and $460 \mathrm{~nm}$.

The molar fraction of HSA-heme-Fe(II)-NO (i.e. $Y$ ) increases linearly with the NO concentration, reaching the maximum $(=1.0)$ at the $1: 1 \mathrm{HSA}-$ heme-Fe(II):NO molar ratio. According to the literature [45], values of $L$ must be lower than the HSA-heme-Fe(II) concentration by at least two orders of magnitude (i.e. $\leq 3.3 \times 10^{-8} \mathrm{M}$ ) [44].

Values of $L, l_{\text {on }}$ and $l_{\text {off }}$ for HSA-heme-Fe(II) nitrosylation [reaction (d) in Scheme 1, and Scheme 2] were obtained either at $\mathrm{pH} 5.5\left(1.0 \times 10^{-1} \mathrm{M}\right.$ Mes buffer $)$ or between $\mathrm{pH} 6.5$ and $\mathrm{pH} 9.5\left(1.0 \times 10^{-1} \mathrm{M}\right.$ Bis-Tris propane buffer) and $20{ }^{\circ} \mathrm{C}$.

HSA-heme-Fe(II)-NO was also obtained anaerobically by keeping the HSA-heme-Fe(II) $\left(3.3 \times 10^{-6} \mathrm{M}\right)$ solution under purified gaseous $\mathrm{NO}(760 \mathrm{mmHg})$, either at $\mathrm{pH} 5.5$ $\left(1.0 \times 10^{-1} \mathrm{M}\right.$ Mes buffer $)$ or between $\mathrm{pH} 6.5$ and $\mathrm{pH} 9.5$ $\left(1.0 \times 10^{-1} \mathrm{M}\right.$ Bis-Tris propane buffer $)$ and at $20^{\circ} \mathrm{C}$ $[24,25,27,30,33,35]$.

\section{Acknowledgements}

This work was partially supported by grants from the Ministero dell'Istruzione, dell'Università e della Ricerca of Italy (PRIN 2007ECX29E_002 and University Roma Tre, CLAR 2009 to P.A.) and from the Ministe- 
ro della Salute of Italy (Istituto Nazionale per le Malattie Infettive I.R.C.C.S. 'Lazzaro Spallanzani', Ricerca Corrente 2009 to P.A.).

\section{References}

1 Sudlow G, Birkett DJ \& Wade DN (1975) The characterization of two specific drug binding sites on human serum albumin. Mol Pharmacol, 11, 824832.

2 Carter DC \& Ho JX (1994) Structure of serum albumin. Adv Protein Chem, 45, 153-203.

3 Peters T (1996) All about Albumin: Biochemistry, Genetics and Medical Applications. Academic Press, San Diego and London.

4 Bertucci C \& Domenici E (2002) Reversible and covalent binding of drugs to human serum albumin: methodological approaches and physiological relevance. Curr Med Chem, 9, 1463-1481.

5 Kragh-Hansen U, Chuang VT \& Otagiri M (2002) Practical aspects of the ligand-binding and enzymatic properties of human serum albumin. Biol Pharm Bull, 25, 695-704.

6 Ascenzi P, Bocedi A, Visca P, Altruda F, Tolosano E, Beringhelli T \& Fasano M (2005) Hemoglobin and heme scavenging. IUBMB Life, 57, 749-759.

7 Fasano M, Curry S, Terreno E, Galliano M, Fanali G, Narciso P, Notari S \& Ascenzi P (2005) The extraordinary ligand binding properties of human serum albumin. IUBMB Life, 57, 787-796.

8 Ghuman J, Zunszain PA, Petitpas I, Bhattacharya AA, Otagiri M \& Curry S (2005) Structural basis of the drug-binding specificity of human serum albumin. J Mol Biol, 353, 38-52.

9 Ascenzi P, Bocedi A, Notari S, Fanali G, Fesce R \& Fasano M (2006) Allosteric modulation of drug binding to human serum albumin. Mini Rev Med Chem, 6, 483489.

10 Yang F, Bian C, Zhu L, Zhao G, Huanga Z \& Huang M (2007) Effect of human serum albumin on drug metabolism: structural evidence of esterase activity of human serum albumin. J Struct Biol 157, 348-355.

11 Zunszain PA, Ghuman J, McDonagh AF \& Curry S (2008) Crystallographic analysis of human serum albumin complexed with $4 Z, 15 E$-bilirubin-IXalpha. $J \mathrm{Mol}$ Biol, 381, 394-406.

12 Ascenzi P \& Fasano M (2009) Serum heme-albumin: an allosteric protein. IUBMB Life, 61, 1118-1122.

13 Curry S (2009) Lessons from the crystallographic analysis of small molecule binding to human serum albumin. Drug Metab Pharmacokinet, 24, 342-357.

14 Curry S, Mandelkow H, Brick P \& Franks N (1998) Crystal structure of human serum albumin complexed with fatty acid reveals an asymmetric distribution of binding sites. Nat Struct Biol, 5, 827-835.
15 Sugio S, Kashima A, Mochizuki S, Noda M \& Kobayashi K (1999) Crystal structure of human serum albumin at $2.5 \AA$ resolution. Protein Eng, 12, 439-446.

16 Bhattacharya AA, Curry S \& Franks NP (2000) Binding of the general anesthetics propofol and halothane to human serum albumin. High resolution crystal structures. J Biol Chem, 275, 38731-38738.

17 Bhattacharya AA, Grune T \& Curry S (2000) Crystallographic analysis reveals common modes of binding of medium and long-chain fatty acids to human serum albumin. J Mol Biol, 303, 721-732.

18 Petitpas I, Bhattacharya AA, Twine S, East M \& Curry S (2001) Crystal structure analysis of warfarin binding to human serum albumin: anatomy of drug site I. $J$ Biol Chem, 276, 22804-22809.

19 Petitpas I, Petersen CE, Ha CE, Bhattacharya AA, Zunszain PA, Ghuman J, Bhagavan NV \& Curry S (2003) Structural basis of albumin-thyroxine interactions and familial dysalbuminemic hyperthyroxinemia. Proc Natl Acad Sci USA, 100, 6440-6445.

20 Zunszain PA, Ghuman J, Komatsu T, Tsuchida E \& Curry S (2003) Crystal structural analysis of human serum albumin complexed with hemin and fatty acid. BMC Struct Biol, 3, 6.

21 Fasano M, Fanali G, Leboffe L \& Ascenzi P (2007) Heme binding to albuminoid proteins is the result of recent evolution. IUBMB Life, 59, 436-440.

22 Fasano M, Baroni S, Vannini A, Ascenzi P \& Aime S (2001) Relaxometric characterization of human hemalbumin. J Biol Inorg Chem, 6, 650-658.

23 Marden MC, Hazard ES, Leclerc L \& Gibson QH (1989) Flash photolysis of the serum albumin-heme-CO complex. Biochemistry, 28, 4422-4426.

24 Kharitonov VG, Sharma VS, Magde D \& Koesling D (1997) Kinetics of nitric oxide dissociation from fiveand six-coordinate nitrosyl hemes and heme proteins, including soluble guanylate cyclase. Biochemistry, 36, 6814-6818.

25 Mattu M, Vannin A, Coletta M, Fasano M \& Ascenzi P (2001) Effect of bezafibrate and clofibrate on the heme-iron geometry of ferrous nitrosylated hemehuman serum albumin: an EPR study. J Inorg Biochem, 84, 293-296.

26 Monzani E, Bonafe B, Fallarini A, Redaelli C, Casella L, Minchiotti L \& Galliano M (2001) Enzymatic properties of human hemalbumin. Biochim Biophys Acta, 1547, 302-312.

27 Fasano M, Mattu M, Coletta M \& Ascenzi P (2002) The heme-iron geometry of ferrous nitrosylated hemeserum lipoproteins, hemopexin, and albumin: a comparative EPR study. J Inorg Biochem, 91, 487-490.

28 Komatsu T, Ohmichi N, Nakagawa A, Zunszain PA, Curry S \& Tsuchida E (2005) $\mathrm{O}_{2}$ and CO binding properties of artificial hemoproteins formed by complexing 
iron protoporphyrin IX with human serum albumin mutants. J Am Chem Soc, 127, 15933-15942.

29 Ascenzi P \& Fasano M (2007) Abacavir modulates peroxynitrite-mediated oxidation of ferrous nitrosylated human serum heme-albumin. Biochem Biophys Res Commun, 353, 469-474.

30 Ascenzi P, Imperi F, Coletta M \& Fasano M (2008) Abacavir and warfarin modulate allosterically kinetics of NO dissociation from ferrous nitrosylated human serum heme-albumin. Biochem Biophys Res Commun, 369, 686-691.

31 Fasano M, Fanali G, Fesce R \& Ascenzi P (2008) Human serum haeme-albumin: an allosteric 'chronosteric' protein. In Dioxygen Binding and Sensing Proteins. M. Bolognesi, G. di Prisco and C. Verde (eds.) pp. 121-131. Springer, Heidelberg.

32 Nicoletti FP, Howes BD, Fittipaldi M, Fanali G, Fasano M, Ascenzi P \& Smulevich G (2008) Ibuprofen induces an allosteric conformational transition in the heme complex of human serum albumin with significant effects on heme ligation. J Am Chem Soc, 130, 11677-11688.

33 Ascenzi P, di Masi A, De Sanctis G, Coletta M \& Fasano M (2009) Ibuprofen modulates allosterically NO dissociation from ferrous nitrosylated human serum heme-albumin by binding to three sites. Biochem Biophys Res Commun, 387, 83-86.

34 Ascenzi P, di Masi A, Coletta M, Ciaccio C, Fanali G, Nicoletti FP, Smulevich G \& Fasano M (2009) Ibuprofen impairs allosterically peroxynitrite isomerization by ferric human serum heme-albumin. J Biol Chem, 284, 31006-31017.

35 Baroni S, Mattu M, Vannini A, Cipollone R, Aime S, Ascenzi P \& Fasano M (2001) Effect of ibuprofen and warfarin on the allosteric properties of haem-human serum albumin. A spectroscopic study. Eur J Biochem, 268, 6214-6220.

36 Fanali G, Pariani G, Ascenzi P \& Fasano M (2009) Allosteric and binding properties of Asp1-Glu382 truncated recombinant human serum albumin - an optical and NMR spectroscopic investigation. FEBS J, 276, 2241-2250.

37 Fanali G, De Sanctis G, Gioia M, Coletta M, Ascenzi P \& Fasano M (2009) Reversible two-step unfolding of heme-human serum albumin: a ${ }^{1} \mathrm{H}-\mathrm{NMR}$ relaxometric and circular dichroism study. J Biol Inorg Chem, 14, 209-217.

38 Hoshino M, Ozawa K, Seki H \& Ford PC (1993) Photochemistry of nitric oxide adducts of water-soluble iron(III) porphyrin and ferrihemoproteins studied by nanosecond laser photolysis. J Am Chem Soc, 115, 9568-9575.

39 Hoshino M, Maeda M, Konishi R, Seki H \& Ford PC (1996) Studies on the reaction mechanism for reductive nitrosylation of ferrihemoproteins in buffer solutions. J Am Chem Soc, 118, 5702-5707.
40 Boffi A, Sarti P, Amiconi G \& Chiancone E (2002) The interplay between heme iron and protein sulfhydryls in the reaction of dimeric Scapharca inaequivalvis hemoglobin with nitric oxide. Biophys Chem, 98, 209-216.

41 Herold S, Fago A, Weber RE, Dewilde S \& Moens L (2004) Reactivity studies of the Fe(III) and Fe(II)NO forms of human neuroglobin reveal a potential role against oxidative stress. $J$ Biol Chem, 279, 22841-22847.

42 Herold S \& Puppo A (2005) Kinetics and mechanistic studies of the reactions of metleghemoglobin, ferrylleghemoglobin, and nitrosylleghemoglobin with reactive nitrogen species. J Biol Inorg Chem, 10, 946-957.

43 Fasano M, Bocedi A, Mattu M, Coletta M \& Ascenzi P (2004) Nitrosylation of rabbit ferrous heme-hemopexin. J Biol Inorg Chem, 9, 800-806.

44 Antonini E \& Brunori M (1971) Hemoglobin and Myoglobin in their Reactions with Ligands. North-Holland Publishing Co, Amsterdam.

45 Anderson SR \& Antonini E (1968) The binding of carbon monoxide by human hemoglobin. Proof of validity of the spectrophotometric method and direct determination of the equilibrium. J Biol Chem, 243, 2918-2920.

46 Ascenzi P, Bocedi A, Antonini G, Bolognesi M \& Fasano M (2007) Reductive nitrosylation and peroxynitrite-mediated oxidation of heme-hemopexin. FEBS J, 274, 551-562.

47 Banci L, Bertini I, Huber JG, Spyroulias GA \& Turano P (1999) Solution structure of reduced horse heart cytochrome c. J Biol Inorg Chem, 4, 21-31.

48 Paoli M, Anderson BF, Baker HM, Morgan WT, Smith A \& Baker EN (1999) Crystal structure of hemopexin reveals a novel high-affinity heme site formed between two beta-propeller domains. Nat Struct Biol, 6, 926-931.

49 Perutz MF (1989) Myoglobin and haemoglobin: role of distal residues in reactions with haem ligands. Trends Biochem Sci, 14, 42-44.

50 Harutyunyan EH, Safonova TN, Kuranova IP, Popov AN, Teplyakov AV, Obmolova GV, Valnshtein BK, Dodson GG \& Wilson JC (1996) The binding of carbon monoxide and nitric oxide to leghaemoglobin in comparison with other haemoglobins. J Mol Biol, 264, 152-161.

51 Brucker EA, Olson JS, Ikeda-Saito M \& Phillips GN Jr (1998) Nitric oxide myoglobin: crystal structure and analysis of ligand geometry. Proteins, 30, 352-356.

52 Miele AE, Santanché S, Travaglini-Allocatelli C, Vallone B, Brunori M \& Bellelli A (1999) Modulation of ligand binding in engineered human hemoglobin distal pocket. J Mol Biol, 290, 515-524.

53 Chan NL, Kavanaugh JS, Rogers PH \& Arnone A (2004) Crystallographic analysis of the interaction of nitric oxide with quaternary-T human hemoglobin. Biochemistry, 43, 118-132.

54 Beetlestone JG, Adeosun OS, Goddard JE, Kushimo JB, Ogunlesi MM, Ogunmola GB, Okonjo KO \& Seamonds B (1976) Reactivity difference between 
haemoglobins. Part XIX. J Chem Soc Dalton Trans, 1251-1278.

55 Bateman H (1910) Solution of a system of differential equations occurring in the theory of radioactive transformations. Proc Cambridge Phil Soc, 15, 423-427.

56 Miranda KM, Espey MG \& Wink DA (2001) A rapid, simple spectrophotometric method for simultaneous detection of nitrate and nitrite. Nitric Oxide, $\mathbf{5}$, 62-71.

57 Herold S \& Kalinga S (2003) Metmyoglobin and methemoglobin catalyze the isomerization of peroxynitrite to nitrate. Biochemistry, 42, 14036-14046.

58 Ascenzi P, Bocedi A, Bolognesi M, Fabozzi G, Milani M \& Visca P (2006) Nitric oxide scavenging by Mycobacterium leprae GlbO involves the formation of the ferric heme-bound peroxynitrite intermediate. Biochem Biophys Res Commun, 339, 450-456.
59 Fasano M, Antonini G \& Ascenzi P (2006) $\mathrm{O}_{2}$-mediated oxidation of hemopexin-heme(II)-NO. Biochem Biophys Res Commun, 345, 704-712.

60 Rohlfs RJ, Olson JS \& Gibson QH (1988) A comparison of the geminate recombination kinetics of several monomeric heme proteins. J Biol Chem, 263, 18031813.

61 Moore EG \& Gibson QH (1976) Cooperativity in the dissociation of nitric oxide from hemoglobin. $J$ Biol Chem, 251, 2788-2794.

62 Sharma VS, Traylor TG, Gardiner R \& Mizukami H (1987) Reaction of nitric oxide with heme proteins and model compounds of hemoglobin. Biochemistry, 26, 3837-3843.

63 Cassoly R \& Gibson Q (1975) Conformation, co-operativity and ligand binding in human hemoglobin. $J \mathrm{Mol}$ Biol, 91, 301-313. 